\title{
Internet Use and Political Efficacy among Chinese University Students
}

\author{
Jin Xuelian \\ Lecturer, College of Media and Arts, Chongqing University of Posts and \\ Telecommunications, China \\ jinxl@cqupt.edu.cn

\section{Yang Deshan} \\ Assistant researcher, International College, Chongqing University of Posts and \\ Telecommunications, China \\ yangds@cqupt.edu.cn
}

\begin{abstract}
This article adopts a multi-case study approach to understand how users of internet technologies actually use the technology, and to explore the extent to which users perceive the technologies' purported democratic and deliberative capacities. In-depth interviews, a focus group, a search and analysis of web content, and digital autoethnography were used to produce qualitative data. Those participants who engaged in online political expression with strangers or on public platforms reported a belief in their competence to make a difference through the internet, while those who did so only with acquaintances, and those who engaged in no political expression online, did not. Most of the participants articulated a strong belief that 'we', internet users as
\end{abstract}

* This paper is developed from the PhD dissertation of the principle investigator (PI: Jin Xuelian), from the Department of Journalism Studies, University of Sheffield. As the PI, I am very grateful to this institution for providing me with a productive environment for my research, and in particular to my supervisor Dr. John Steel who encouraged the project from the outset. This paper would not have come to fruition if not for the critical and constructive comments from Prof. Jackie Harrison, Dr. Florian Schneider, Prof. Ang Peng Hwa, and Prof. Hao Xiaoming. I am greatly indebted. Yang and I also wish to express our deep gratitude to The National Social Science Foundation of China, Chongqing Municipal Education Commission, Chongqing Association of Social Sciences, and our current employer, Chongqing University of Posts and Telecommunications, for funding and supporting this research.

(C) JIN XUELIAN AND YANG DESHAN, 2016 | DOI 10.1163/22142312-12340056

This is an open access article distributed under the terms of the Creative Commons Attribution- 
a whole, are influential, because they believed online public opinion contributed to better solutions to some social problems. This study casts new light on the relationship between internet use, political attitudes, and online political expression.

\section{Keywords}

internet use - internal political efficacy - enactive experiences - collective political efficacy - online public - China

\section{Introduction}

The rise of the internet has revived scholastic enthusiasm for the social and political influence of information and communication technologies (e.g. Dahlgren 2005; Guo et al. 2007; Papacharissi 2002; Yang 2003). There has, however, been very little research concerning the individual-level consequences of internet use (e.g. Velasquez \& LaRose 2015; Lee 2006; Richey \& Zhu 2015). Empirical studies tend to treat internet use as a whole (e.g. Dutta-Bergman 2005; Shah et al. 2001), or group internet use into rough categories like social media use, information use, and entertainment use (e.g. Norris \& Jones 1998; Shah et al. 2001). Such a simplistic view of internet use overlooks the rich details and nuanced differences of users' online experiences. Adopting a multi-case study approach, this article focuses on how individuals utilize the internet differently to meet their own needs and how they understand the influence of their usage. As a result, the article contributes to a better understanding of subtle and nuanced differences of individuals' internet use, and it helps to explore how these differences might discriminate individual-level effects, using rich and detailed data.

Due to the scope of this article, this study only focuses on findings concerning how the internet and internet use, facilitate Chinese university students' efficacy beliefs. The article makes three original contributions to better understanding the relationship between internet use and political efficacy. Firstly, this study finds that different types of online political expression and social media use are associated with internal political efficacy in various ways. The findings also reveal that anonymity of online political expression and the networking capacity of the internet to allow its users to reach an audience beyond their real life social networks encourage political expression and thus can increase their levels of internal political efficacy. In addition, the results demonstrate how the internet serves as a mechanism that fosters imagined 
communities among its users and how the sense of belonging to an imagined community boosts internet users' collective political efficacy and social media political efficacy.

The findings left unaddressed in this article include: practical and ideological reasons for university students' online political disengagement; certain usage patterns across various internet applications; and 'democratizing' implications of seemingly trivial online exchanges, online entertainment, and political disengagement.

\section{Literature Review}

\section{How Do Individuals' Feelings and Beliefs Affect Their Political Participation?}

Political efficacy concerns individuals' feelings about, and beliefs in, themselves and in the political system that affect their willingness to perform their political rights and obligations. Political efficacy pertains to a citizen's belief in affecting the political system. Campbell and Miller (1954: 187) conceptualize political efficacy as the 'feeling that individual political action does have, or can have, an impact upon the political process, namely, that it is worthwhile to perform one's civic duties.' Political efficacy is split into two parts, internal and external. Internal political efficacy concerns personal beliefs regarding the ability to achieve desired results in the political domain through personal engagement and an efficient use of one's own capacities and resources. External political efficacy concerns people's beliefs that the political system is amenable to change through individual and collective influence. Whereas internal political efficacy mostly concerns the degree of influence that people perceive themselves to be able to exert due to their own capacities, external political efficacy concerns the degree of influence people perceive themselves to be able to exert due to the actual functioning of the political system (Caprara et al. 2009). Internal political efficacy can be also referred to as an 'individual's sense of political self-competence' (Finkel 1985: 893). External political efficacy is closely linked to political trust (Ibid.). Iyengar (1980) suggests that external political efficacy is part of Easton's concept of diffuse political support.

Social cognitive theory holds that 'personal agency operates within a broad network of sociostructural influences' (Bandura 2001: 266). In light of social cognitive theory, measurements of efficacy beliefs should consider the context and the specific mode of political participation they predict (Bandura 1997; Wollman \& Stouder 1991). In order to better understand social media activism and collective activism, scholars have developed the concepts of social media political efficacy and collective political efficacy (Velasquez \& LaRose 
2014, 2015). Social media political efficacy refers to 'individuals' perceived capabilities to use social media effectively to achieve their political objectives' (Velasquez \& LaRose 2015: 457). Collective political efficacy is defined as 'a group's shared belief in its capabilities to perform specific courses of action in order to produce a desired goal' (Velasquez \& LaRose 2014: 903).

Political efficacy has been deemed important in influencing political behaviour. There is abundant research and empirical evidence (e.g. Caprara et al. 2009; Cohen et al. 2001) that supports a positive correlation between both types of efficacy and various forms of political participation. However, there are scholars who argue that the influence of internal and external efficacy is mixed. It seems that all studies support a positive relationship between internal political efficacy and all types of political behaviours, while the effect of external political efficacy is complex. External political efficacy is positively related to conventional, conformist, and low initiative conventional participation (Abramson \& Aldrich 1982; Bennett 1975) and negatively related to unconventional, non-conformist, and high initiative conventional participation.

Existing literature supports the idea that efficacy has strong effects on the likelihood of participation (e.g. Almond and Verba 1963; Caprara et al. 2009). However, little is known about what factors increase or decrease feelings of efficacy, since very little literature treats political efficacy as a dependent variable (Finkel 1985; Wu 2003).

\section{Internet Use and Political Efficacy}

Due to the explanatory power of efficacy on political behaviour, the study of how internet use affects political efficacy and how internet use affects political participation mediated by political efficacy has attracted wide attention. It has been found that having access to the internet, or generally using the internet, does not increase levels of political efficacy (Richey \& Zhu 2015). However, political use of the internet is positively related to levels of internal political efficacy, while entertainment use is not (e.g. Lee 20o6; Velasquez \& LaRose 2015). The former includes online exposure to political information, political expression, and contacting political figures.

Velasquez and LaRose (2015) try to interpret these finding from a social cognitive theory perspective. They argue that enactive experience 'allows individuals to learn through their own experience the reach of their own capabilities.' Therefore, successful enactive experience is 'the most powerful source' of internal political efficacy beliefs (Velasquez \& LaRose 2015: 458). The socioeconomic status model provides another interpretation of the phenomenon. The socioeconomic status model is 'broadly accepted as a basic model of participation' in the discipline of political science (Leighley 1995: 181) and 'one of the most robust findings' (Stanley \& Weare 2004: 509). The model emphasizes 
'individuals' socioeconomic status and civic orientations as predictors of participation' (Leighley 1995: 181) and suggests that the 'use of communication technologies can have, at best, limited additional explanatory value' (Stanley \& Weare 2004: 509; Verba \& Nie 1972; Verba et al. 1995). Due to the commercial nature of the internet, its earlier diffusion favours high-status individuals. Therefore, the higher levels of efficacy and higher likelihood of participation of internet users with certain use patterns found in earlier literature (e.g. Quintelier \& Vissers 2008) may be better explained by the high socioeconomic status of earlier internet adopters than their internet use. That is to say, earlier adopters of the internet are high-status individuals. They tend to be more politically active and have higher levels of efficacy. For the late adopters, internet access does not increase their levels of political efficacy (Richey \& Zhu: 2015). It is difficult for survey research to establish any causal link between internet use and efficacy, and even more difficult to explore the mechanism of how internet use facilitates or reduces efficacy.

Like traditional studies of how efficacy influences political participation, studies in the context of internet use also report mixed findings (see, for example, Brunsting \& Postmes 2002). The conceptualization and influence of efficacy beliefs is not contextless; nor is political communication. Empirical studies suggest that efficacy beliefs tailored to specific participation behaviour are better predictors than general political efficacy. For example, social media political efficacy is found to have 'a stronger relationship with social media activism than the global measure of political efficacy' (Velasquez \& LaRose 2015: 467). Limited literature focuses on the mechanism of how specific internet use facilitates individuals' efficacy beliefs (e.g. Velasquez \& LaRose 2015).

\section{Methodology}

Instead of applying the existing normative conceptions formulated in the context of democratic countries with idealized deliberative aspirations, this article adopts a multi-case study approach to understanding how users of internet technologies actually use the technology and explore the extent to which the technologies' purported democratic and deliberative capacities are perceived by the users. Twelve participants (see Table 1) were recruited from three universities in the City of Chongqing, in the southwest of China. In-depth interviews (from 22 February to 3 March 2012), a focus group (6 March 2012), a search and analysis of web content, and digital auto-ethnography ${ }^{1}$ were used

1 This means that the principle investigator used all internet applications the twelve participants reported they used in order to understand their online experience. 
TABLE 1 The participants

\begin{tabular}{|c|c|c|c|c|c|}
\hline Pseudonym & Gender & Course & Yos & $\begin{array}{l}\text { Fānqiáng } \\
\text { (翻墙) }\end{array}$ & Catshs \\
\hline Xiaoming & Male & $\begin{array}{l}\text { BA in telecommunication } \\
\text { engineering }\end{array}$ & 3 & No & Science \\
\hline Jinsong & Male & $\begin{array}{l}\text { BA in electrical engineering } \\
\text { and automation }\end{array}$ & 2 & No & Science \\
\hline Bokai & Male & $\begin{array}{l}\text { BA in electrical engineering } \\
\text { and automation }\end{array}$ & 2 & No & Science \\
\hline Yanru & Female & BA in finance & 4 & No & Science \\
\hline Shuhan & Female & BA in English & 4 & No & Science \\
\hline Yuhao & Male & BA in English & 1 & Yes & Social science \\
\hline Qinglan & Female & Ms in computer science & 3 & No & Science \\
\hline Yimo & Female & $\begin{array}{l}\text { BA in mathematics \& digital } \\
\text { technology }\end{array}$ & 1 & No & Science \\
\hline Chenjie & Male & MA in law & 1 & Yes & Social science \\
\hline Boyu & Male & $\begin{array}{l}\text { BA in biological medicine } \\
\text { engineering }\end{array}$ & 4 & No & Science \\
\hline Yawen & Female & $\begin{array}{l}\text { BA in broadcasting and } \\
\text { television }\end{array}$ & 3 & No & Social science \\
\hline Chenqiang & Male & BA in English & 2 & No & Science \\
\hline
\end{tabular}

NOTES: YOS = YEAR OF STUDY; FĀNQIÁNG (翻墙) $=$ CLIMBING OVER THE GREAT WALL ${ }^{2}$ CATSHS = COURSE AT SENIOR HIGH SCHOOL

to produce qualitative data in order to provide detail about internet use and understanding of the implications of its use for the participants.

\section{The Sample}

The research focuses on current home university students, who constitute a crucial proportion of internet users in China, and some of whom may eventually play important roles in Chinese society. As Yee claims, 'a systematic study of contemporary Chinese university students' political culture will cast some light on China's future political development' (Yee 1999: preface). All participants

2 This 'literally means crossing the wall, but is commonly translated as 'climbing over the Great Firewall' - that is, evading the network of technical controls by which China regulates foreign Internet content' ( $\mathrm{Ng}$ 2013). 
were from universities in Chongqing. These universities were chosen to avoid potential biases that studies of Beijing and Shanghai could have introduced, given that university students in a metropolis at a regional level are more representative of the population (see Cockain 2014: 53; Guo et al. 2007).

A well-designed sampling procedure and recruitment strategy is crucial to the success of the in-depth interview, due to the small size of the sample. Sampling in the initial stage of a qualitative study follows two major rules: go to where the studied phenomenon occurs and go to the information rich (Coyne 1997). The principle investigator, therefore, decided to recruit her initial sample from a university campus. For the second rule, an informationrich participant for qualitative research is 'articulate, reflective, and willing to share with the interviewer' (Morse 1991: 127). The voluntary participants are believed to belong to a group of people who would maximize the possibilities of obtaining the maximum amount of data (Glaser 1978; Strauss \& Corbin 1990). A volunteering sampling strategy was employed and no reimbursements were promised to ensure that initial participants were those who were truly willing to talk about the research topic. Initial recruitment was conducted at Chongqing University of Posts and Telecommunications by handing out leaflets of invitation to interview. Fifty leaflets were distributed on the main road to the central canteen and three students volunteered to participate.

After analysing the first three participants' data, three more participants were recruited. They were a female student majoring in finance, a female student majoring in English, and a male student majoring in English who regularly engaged in 'Fanqiang' (翻墙; climbing the Great Wall). The purpose was to explore whether gender, learning English as a major, and regular exposure to the purportedly more liberalized internet would help to further clarify the categories developed from the first phase, or whether these factors would introduce new categories.

Analysis of the six in-depth interviews yielded saturated categories, but also left one research question under-explored. None of the six interview participants talked much about the political, cultural, or social influence of the internet in mainland China, or that of their internet use when the interviewer allowed them to lead the conversation and talk about their understanding of their online activities in their own words. Therefore, further information was needed to collect data about the participants' understanding of the political, cultural, and social influence of the internet in mainland China and that of their internet use.

The principle investigator decided to employ a focus group for furtherdata collection. The focus group was geared to explore the participants' understanding 
of the internet's influence. Three reasons contributed to the decision to choose a focus group: firstly, the exploratory nature of focus groups; secondly, the focus group concentrates on a specific topic and provides deeper insight; and finally, group dynamics generate richer data than single individual interviews. The focus group is believed to be best for exploratory research (Stewart \& Shamdasani 1990). The meaning of 'exploratory' here is twofold (Morgan 1988). It means either that 'the topic or study population has not been extensively studied,' or that well-studied topics have not been researched from the participants' perspectives (Ibid.: 30).

The exploratory nature of the focus group serves the methodological approach and the purpose of the research well. Instead of imposing the researcher's view on the participants, focus groups allow the participants to discuss the topic in their own words (Stewart \& Shamdasani 1990) or in their natural vocabulary (Morgan 1988). They serve to obtain large amounts of rich data from the perspectives of the participants and provide the researcher with unforeseen information (Lippa 2008), and thus new knowledge to understand the research topic. For this specific focus group, six participants were recruited from six colleges within a university by their tutors. Pre-set criteria were used based on analysis of data generated from in-depth interviews. Analysis of interview data illustrates that Fanqiang and learning English as a major have a significant impact on participants' choice of online information sources, and the following criteria were used for sampling participants: the group would have to include one English major, a non-English major who was a regular user of a proxy server, and a non-English major who was once a user of a proxy server. According to the findings of the in-depth interviews and existing literature, gender, course, and grade are all factors that affect internet use (Hong et al. 2007), political interest (Bennett \& Bennett 1989), and political participation (Tong 2003). Therefore, these three criteria were used to select participants (see Table 1).

\section{Ethical Issues}

Ethical issues are of critical concern to this project as it involves some politically sensitive topics in China and was carried out at a politically sensitive time. The interviews and the focus group were conducted before the 18th National Congress of the Communist Party of China, which was held in November 2012. There was a transition of power from the fourth generation of leadership to the fifth. Factions within the Party were in a critical period of competing for power. The incident of Wang Lijun and Bo Xilai drew international attention to China, especially to the transition of power. When we consulted The Times on 
14 June 2014, a key word search with 'Wang Lijun' resulted in 102 articles and a search for 'Bo Xilai' produced 345 articles.

On the afternoon of 6 February 2012, Wang Lijun, a vice mayor and a flamboyant former police chief of Chongqing, the fourth municipality directly under the Central Government and one of the biggest cities in China, fled, alone, into the us consulate in Chengdu, the nearest to Chongqing, and walked out at 23:35 the next day. Wang Lijun was sentenced to 15 years in prison for a series of crimes including defection, bribe-taking, abuse of power, and bending the law for selfish ends' on 18 September 2012 (Xinhua News 2012). The Wang Lijun incident triggered the worst political scandal in two decades in China (Ibid.) and led directly to the fall of Bo Xilai, one of the top communist politicians. Bo Xilai was then Chongqing's Communist Party Secretary, the highest-ranking official at municipal level, and also had a seat on the Politburo Standing Committee, which at the time had nine members and is the top decision-making body in China. He 'rose to nationwide prominence with an anti-mafia crusade' led by Wang Lijun and 'mass sing-alongs of communist anthems' (Bodeen 2012). He had had the chance of promotion to the highest ranks of power in China before the Wang Lijun incident (Ibid.). Investigations into Wang Lijun revealed Bo's bribery, embezzlement, and abuse of power, and Bo Xilai was 'sentenced to life in prison for corruption and abuse of power' on 22 September 2013. Gu Kailai, Bo Xilai's wife, was found guilty of murdering Neil Heywood, a British business man and was given a death sentence with a two-year reprieve on 9 August 2012.

During that period, participants might have had safety concerns about discussing such a politically sensitive topic with a stranger or within a group. To minimize the effect, participants were notified about the topic when they were recruited, to make sure that they would be willing to talk about it. Also, the principle investigator opened her Renren space and QQ space to potential participants for them to find out more about her and to make them feel safe to participate. The research also involves personal and confidential information. Therefore, the participants were coded, using pseudonyms, and remained anonymous in any data collected. The data were highly confidential and accessible to the principle investigator only. Anonymity made it possible to 'actively protect the identity of research participants' (King \& Horrocks 2010: 117) and encouraged the participants to feel safer and more comfortable to share as much as possible about their online experience and their understandings.

\section{Data Collection and Analysis}

The design of data collection begins with the question of what constitutes data for the research. For this article, the research consists of three categories 
of data: participants' detailed narratives of their online experience and interpretations; information about online content the participants encounter and the internet applications they use; and the principle investigator's memos. The first category of data was collected through six in-depth interviews and one focus group; the second and third categories were collected by searching and analysing web content that participants reported, and through digital ethnography. Data collection and analysis were simultaneous and were shaped and reshaped throughout the research. Collection of the first category data was the main thread that sewed together the collection of the other two categories of data and analysis.

The principle investigator conducted one-on-one face-to-face semistructured interviews with the first three volunteering participants, and these open-ended, in-depth interviews were organized in a cosy and quiet university consulting room. After introductions and opening questions about the demographic features and online skills of the participants, the participants were asked to list all of their online activities. Every online activity and understanding of the participants was investigated in great detail in order to minimize the influence of existing literature and the bias of the researcher, as political implications of the internet could exist in various ways. Every conversation was recorded, with the consent of the participants. Brief note-taking was done during the course of the conversation to catch important information for the later process of transcribing and analysing, and to develop further questions in the process of the interview. Due to the open nature of the questions, the lengths of the three interviews were respectively 142 minutes, 57 minutes, and 60 minutes.

Each recorded interview was transcribed using NVivo 10, either right after the interview or on the second day after it was conducted, in order to minimize the effect of memory distortion. All transcriptions were created by the principle investigator to minimise mis-transcription of the conversation and also so that the principle investigator could further familiarize herself with the data. At each phase of coding, data about the content participants were exposed to and the applications they used were collected through online search and analysed through methods of content analysis or text analysis when appropriate. The other three interviews were also conducted by in cosy, quiet university cafes that were convenient for the participants. Their interviews lasted 35, 89, and 110 minutes, respectively.

The focus group was conducted in a meeting room at Chongqing University of Posts and Telecommunication. During the focus group, responses were collected to the following questions: 
1) Please list all your online activities and describe them in detail.

2) How do you think the internet has been influencing Chinese society?

3) How do you think the internet has been influencing the political system in China?

4) How do you think the internet has been influencing culture in China?

The participants were given several minutes for each question to write down their answers and then presented their answers one by one. After the presentation, they were asked to discuss the questions further. The group discussion lasted 101 minutes. The data from the focus group went through the same analysis process as the interviews.

In short: six in-depth interviews and one focus group supported and supplemented by web content analysis and digital ethnography produced rich and detailed data to answer the research question.

\section{Findings}

\section{'My Internet Use Has an Effect on Society'}

Those participants who shared, generated content, or conversed about politics and public affairs with strangers or on public platforms reported a sense of internal political efficacy. They articulated the belief in their influence through the internet, while those who did so only with acquaintances or those who did not engage in any political expression online at all expressed disbelief in it.

Political expression refers to sharing, generating content, or conversing about politics or public issues. From the qualitative data that informs this study, the principle investigator was able to identify three patterns of online political expression and classify six participants into three categories according to their patterns of online political expression. Category I includes Xiaoming and Yuhao, who reported conducting political expression on public platforms or with strangers online. Public platforms refer to social media on which a post can be seen by all registered users once posted, for example forums or bulletin board services. Strangers are people who individuals do not know in real life, whereas acquaintances are those who they do know in real life. Category II includes Jinsong and Yanru, who articulated online political expression only between themselves and their acquaintances. Category III includes Bokai and Shuhan who did not report any online political expression.

Xiaoming, in cateogry $\mathrm{I}$, reported that he read on his university forum 'information relevant to our course, our university, or us university students, for example an article about the Mayor's opinion about high internet fees 
in universities', and 'what schoolmates posted (about what happened on campus), for example what happened in a certain university canteen, unqualified food, complaints about the university (usually trivial matters).' He said that he would 'write something' (comments or experiences) if he 'knew about the issue' other schoolmates posted about. He also reported sharing on his Sina Weibo microblogging account (新浪微博) news from the Southern Weekly website, ${ }^{3}$ satirical pictures and cartoons, political news, news about public issues, and other users' comments on political or public issues, and he also reported supporting other users' posts about political or public issues when they attracted many followers. He stated that his Sina Weibo account had 138 followers among whom all, except for one or two acquaintances, were strangers. He said that he just shared what he read, but he did not comment on what he shared.

Yuhao said he would express 'opinions and demands through tweeting, retweeting, commenting, and voting online.' He reported having shared and produced content, and communicated about politics and public issues, on his Sina Weibo account and on Baidu Tieba, ${ }^{4}$ a public platform. His Weibo account had more than 400 followers. Among them, about 100 were acquaintances, about ten close friends, and the others were all strangers. He reported commenting on a great variety of issues including forced demolition ${ }^{5}$ (qiang chai 强拆),

3 This is a news portal of a traditional medium affiliated with the government, however, it has been described by The New York Times as 'China's most influential liberal newspaper' (Rosenthal 2002) as a result of commercialization and deregulation (Donald et al., 2002). It remains an open question whether the paper can maintain this reputation in the wake of a 2013 dispute over censorship and Party influence on the paper.

4 This is one of the most popular online forums or communities in China. It is based on the notion of bringing like-minded people together to communicate with, and help each other on a topic of common interest through key word search. Any registered user can search with a key word the topic he or she is interested in. If such a forum, or so-called bar, has not been established, a forum named by that key word is automatically set up. Once the bar is created, it will become searchable within Baidu Tieba. As a result, it claimed to have 8,192,794 topicbased forums when the authors consulted the website (http://tieba.baidu.com/) on 10 May 2014. Liyi Bar, one of its most popular bars, has 10,184,593 visits and 421,951,261 posts.

5 This refers to violent and bloody home demolitions by property developers with licences issued by the government. For example, the English version of People's Daily Online (Remin wang人民网) reported two such cases on 2 November 2010: 'A man set himself on fire in protest in Northeast China and another man in North China was beaten to death after he refused to move out' (http://en.people.cn/90oo1/90776/90882/7184269.html). On 26 September 2011, the English version of сCTV (China Central Television) online reported that 'fifty-seven officials, including one at vice-provincial level, were punished by the 
urban management officers ${ }^{6}$ (chengguan 城管), live extraction of bear bile, ${ }^{7}$ and so on. For example, he commented that 'North Korea is a shameless country. It does not develop its own economy. Instead, it asks for money from other countries by nuclear threatening,' when he retweeted the news that North Korea stopped a nuclear test after receiving something from the Us. He also commented that 'what is happening in Syria demonstrates how a number of countries involve play the game [of politics].' He read a piece of news about a child beggar in China, and then he made comments comparing the state of children's welfare in America with that in China.

It was two days before the opening of the Chinese People's Political Consultative Conference ${ }^{8}$ (Zhongguo renmin zhengzhi xieshang huiyi 中国人 民政治协商会议) and the conference of the People's Congress (Renmin daibiao da hui 人民代表大会) when Yuhao was interviewed on 3 March 2012. He reported that he made lots of comments on the news of the two upcoming events. For example, he commented on the news about Liu Xiang's ${ }^{9}$ fourth absence from the Political Consultative Conference in his five-year term as a delegate, and that some members of the People's Congress were caught dozing in previous conferences. ${ }^{10}$ He commented on his Weibo: 'Liu Xiang is

government for malpractice that led to death or injury in 11 cases of forced demolition this year' (http://english.cntv.cn/20110926/105371.shtml; both sources last accessed 2 July 2016).

6 There had been videos, photos, and news online showing China's urban management officers beating illegal vendors, raising criticism of their use of excessive force and questionable tactics.

7 Animal rights activists protested against the extraction of bear bile from live bears, calling for opposition to Guizhentang, China's biggest bear bile company, going public on the stock market.

8 This is a political advisory body in the People's Republic of China. The organization consists of delegates from a range of political parties and organisations, as well as independent members. The proportion of representation of the various parties is determined by established convention, negotiated between the parties. In practice, the largest and dominant party in the conference is the Communist Party of China, which has about one third of the seats.

9 Liu Xiang is a famous Chinese athlete who became the first Asian to win the Olympic men's 110m hurdles at the 28th Athens Games.

10 There were a considerable number of reports and comments online on some representatives of the Chinese People's Political Consultative Conference and the People's Congress dozing in the conferences since 2008 , and on the dual nationality of some representatives of the two conferences and their offspring. These reports and comments raised wide concerns and doubts about whether these representatives of the people did represent their people in the important decision-making processes in China. 
an athlete. His major responsibility is training and winning honours for the country, not dozing in such conferences'; 'Politics in China is funny. It drags every famous person who has not become another country's citizen yet to conferences. (That is) nonsense'; 'The conference of the People's Congress is the Chinese overseas students' parents' meeting.'

Yuhao reported that he also produced original posts on politics on Sina Weibo. He gave an example. He wrote about an anti-Party demonstration in Hong Kong. He said:

We (he and his couch-surfing friend in Hong Kong) were at Causeway Bay, Hong Kong. At that moment, two contrasting demonstrations were taking place there. On one side, it was the celebration of Hong Kong's Return to China. On the other side, it was the (anti-Party) demonstration. I felt so excited. I saw Hong Kong people demanding general election and protesting the interference of the mainland Chinese government in the election of their Legislative Council, their power, and their demands. They have the environment and conditions to express what they really think. Lots of participants are young students. I felt the power of democracy and I was inspired. And then I tweeted it on Weibo.

His reports show that he also interacted with others on Weibo. He said:

Sometimes people will interact with you after reading your comments. Sometimes they support you; sometimes they do not. There are many opportunities for interaction on Weibo. Those who interact with you are those who follow you, or those who see your comments following the original tweets. They express agreement or disagreement on your comments. They are all strangers.

For example, he reported that he had political discussions with a history teacher in Sichuan University and a Taiwanese student in mainland China.

Jinsong, in category II, reported that he sometimes shared reports about social issues and made comments online through his accounts on Qzone, ${ }^{11}$ Sina Weibo, Tencent Weibo, or Renren (the 'Facebook' of China). He said that

11 Qzone is QQ's version of Facebook, but much more personalized. It claims to be the biggest online social network in China. Qzone users can play games, make up and dress their QQ image, upload photos, and write blogs and single sentences, called saysay (say something). Tencent $\mathrm{QQ}$ is an internet-based instant messaging platform. It is the biggest online instant messaging service provider in China, with $76.2 \%$ market share. 
he commented on 'news relevant to university students', 'some current affairs', 'celebrities' comments on current affairs', 'news reports about current affairs', and 'others' comments'. He said:

I share some reports about current affairs, for example, the Xiaoyueyue Accident. ${ }^{12}$ I tweet about my opinions on Sina Weibo. I hope that people say 'no' to apathy. People should lend a helping hand even when there might be a cost or something. I think that everybody should help others without considering one's own loss.

He said that he randomly chose one of the four platforms to share what he read and his comments. But his posts were only available to his acquaintances. $\mathrm{He}$ said that he did not like to accept strangers to be his contacts.

Yanru, in category II, reported that she had more than 200 followers on her Sina Weibo and she posted a great variety of things including love, career, food, and amusement in Chongqing, fashion street shoots, beautiful places with pictures, pretty dogs, interesting sentences, and her feelings. But when it came to politics or social issues, she only conversed online with her boyfriend, her close friends, or her classmates. For example, she reported that she chatted about the Xiaoyueyue Accident with her classmates on Sina Weibo. She said:

One of my classmates posted, 'This must be (not true, but) a film. How could it be possible? There have been so many people passing by without helping (the little girl).' I posted, 'I think so. They haven't helped when they obviously saw her.' (We) just posted a few words. Nothing more afterward. (It is) just a topic for chatting.

12 The Xiaoyueyue Accident: Wang Yue (王悦) was a two-year-old Chinese girl who was run over by two vehicles on the afternoon of 13 October 2011 in a narrow road in Foshan, Guangdong. As she lay bleeding on the road for more than seven minutes, at least 18 passers-by skirted around her body, ignoring her. She was eventually helped by a female rubbish scavenger and sent to a hospital for treatment, but succumbed to her injuries and died eight days later. The closed-circuit television recording of the incident was uploaded to the internet and quickly stirred widespread reaction in China and overseas. The accident was widely covered by English media such as the ввс (Yip 2011), The Guardian, The Wall Street Journal, and The Telegraph. However, some people online questioned the closed-circuit television recording. At the time the accident occurred, the visibility of the scene was very bad. A close examination of the recording shows that the passers-by could hardly recognize the injured little girl, but this opinion was largely ignored. 
There was an exception. She mentioned that she retweeted the Wang Lijun Incident on her Weibo. She said:

I retweeted the Wang Lijun Incident because I thought that he was a good man. My classmates retweeted it too, saying something like that he was set up and was a sacrificial lamb. (I) think that he is good and then retweeted.

But she added:

There was a video on Weibo. It was the comments made by the State Department of the USA. There was no news report about it in China because of the blockade. My parents checked Lianhe Zaobo ${ }^{13}$ online, which analysed the reasons. I told my boyfriend when I knew about it and said, 'Wang Lijun is such a good man. Why should he be in prison?' But I dared not tell others. To tell others such things, you know the situation in China, well, is of no use, and might be sent to prison. So, usually I do not make improper comments, just talk at home.

Bokai and Shuhan, in category III, did not report any online political expression throughout their interviews.

Interviewees who fell into category I articulated a sense of internal political efficacy and they were also explicit that their influence was small, while interviewees in the other two categories did not. Xiaoming expressed his belief in his influence through the internet, saying 'my internet use has an effect on society'. He explained:

I share such news (about corruption or other misconducts of the government) because I want to let others know. I want to make them angry so that they make comments. I do not want to make comments because I lack words to express myself well. My support and sharing of the posts can help to raise concerns about the issues. My support and sharing of the posts has effects.

However, he claimed that the influence of his sharing was 'extremely small,' and explained, 'I can only show my concern (about the issues), but cannot influence the decision-making of the government.'

13 A Singapore based Chinese newspaper (http://www.zaobao.com.sg; last accessed 2 July 2016). 
Yuhao also expressed belief in his ability to influence others through the internet and exhibited intentional moves to cast that influence. He said, 'there are things that I want to make an effort to change [...] and to make my contribution, to express my demands and also let my followers know my demands in a hope to make a difference.' According to his articulation, he had a clear conscience about how he exerted his influence - through his followers - which demonstrated his belief that he was capable of influencing his followers. He also voted regularly, usually once every week or two, on Sina Weibo's petitions. He said, 'if I make my opinions known online, I may bring about some changes, for example, to live bear bile extracting or homeless dogs. There may be a possibility for change through expressing what I think.' Therefore, he said, 'I vote if I see some issues I know about or I am interested in. The issues I voted on include Guizhentang live bear bile extracting, homeless dogs, homeless children, and the singing 'red' songs campaign in Chongqing.'14 However, he also claimed that his influence was small. When he was asked to score the degree of his influence through the internet, he said, 'probably 1 out of 100 . There must be some effect.'

Interviewees in categories II and III did not show a sense of internal political efficacy. Bokai said, 'comments on certain issues cannot bring good effects.' Yanru gave her opinion:

I do not think that it is of any use to retweet what happens in China. I do not feel that I can control [anything] [...] I think that it is of no use to retweet other issues that involve inequality. Anyway it is of no use to say something. It does not change anything.

Shuhan expressed the same disbelief, saying 'I do not think that the result will be different because I read it or care about it.' Jinsong did not express any concern about achieving any political objective. He said that his purpose was to share comments about social issues and to be close with those 'who shared the same ideas' as him.

This was a campaign to sing revolutionary era songs mandated by Bo Xilai, the party secretary in Chongqing from November 2007 to March 2012. It is a part of a bigger campaign of singing (revolutionary songs), reading (classic books), telling stories (of the communist party), and transmitting quotes from Mao's Little Red Book by text message to everyone in Chongqing. Bo Xilai also 'erected statues of Mao throughout the city, in addition to reorienting the city's economy around state-owned industries.' Bo Xilai and his campaign was criticised by 'the Chinese Right (free-market, pro-individual rights, anti-Maoist liberals) as the New Left who argued against the incorporation of capitalist principles into the Chinese economy' (Ng 2013: 20-21). 
Xiaoming and Yuhao's articulations also help explain why online political expression on public platforms or with strangers contributes to a stronger sense of internal political efficacy. Xiaoming explained that anonymity on a public platform and with strangers freed him. He said, 'I am concerned about how people see me on a platform of acquaintances.' In addition, the internet extends its users' social networks beyond their offline circles and makes them feel that their voices can be heard by more people. Yuhao's QQ contacts and QQ groups are acquaintance-only platforms. When explaining why he did not share a call for help to find matching blood for ill people, he said, 'it does not help to share it in QQ groups, there are a limited number of people in a QQ group.' On the contrary, he believed that sharing social or political issues on a public platform or with strangers could make a difference.

It is worth adding here that participants' perceptions of censorship are an important factor affecting their online political expression and thus internal political efficacy. According to Shuhan and Yuhao, their understanding of what is permissible on a public platform with strangers, and what is not, greatly affects their choices of what to post on various platforms. When Shuhan explained why she did not post on Sina Weibo what her parents found on Lianhe Zaobo about the Wang Lijun Accident, she said, 'but I dared not tell others. To tell others such things, you know the situation in China, well, is of no use, and (I) might be sent to prison. So, usually (I) do not make improper comments. (I) just talk at home.'

Yuhao reported that he experienced censorship and the experience had a great impact on his choice of what to post. He said, 'My post was deleted once and then I dared not post something sensitive.' What was deleted was his post about the anti-Party demonstration in Hong Kong. He said, 'I felt the power of democracy and I was inspired. And then I tweeted it on Weibo. It was deleted. I was scared and then dared not do so.' He was explicit about the effect of censorship:

Sometimes I worried about surveillance when using the proxy server. I turned the page off right after viewing and would not make any comments. [Censorship] does not affect what I view, but it does affect what I retweet and tweet.

\section{'My Concern Does Not Make a Difference, but the Concern of Many People Will Turn Out to Be Powerful'}

Most of the participants articulated a strong belief that 'we', internet users as a whole, are influential, because they believed that online public opinion did contribute to better solutions to some social problems. 
There is evidence that the internet helps to develop a sense of 'we, the online public', among its users. Nine out of twelve participants used the terms 'we', 'us', and 'the public' to refer to those people like them who show their concern about social issues online by viewing or sharing relevant information, or by expressing their opinions. Moreover, they believed in the power of their attention and concern. As Xiaoming put it:

I don't know how the pressure of public opinion works, but I think that it has an impact when an issue attracts attention from many people. That is why I am concerned about [social and political issues]. When an issue attracts lots of people's attention, it can attract the attention of relevant government departments.

And their belief came from the unique nature of the internet, which allows its users to voice and share their opinions. Jinsong explained:

There should be an effect if an issue attracts the attention of a large number of people. An issue can attract more people's attention through one-to-many spreading online. Like what the advertisement ${ }^{15}$ says, 'my concern does not make a difference, but the concern of many people will turn out to be powerful.' Some people will make comments. Some will know the facts and will form their own opinions after reading the comments. If an issue attracts my attention, in my view, it has an effect.

Chenjie was quite explicit, saying, 'different from traditional media like newspapers, broadcasting, and television, the internet empowers its users by allowing them to voice their opinions.' Yuhao gave an example:

If the decision to build the Three Gorges $\operatorname{Dam}^{16}$ (San Xia Da Ba 三峡 大坝) was placed in today's context, lots of scholars who have no

15 It was not clear from the interview which advertisement Jinsong had in mind.

16 The Three Gorges Dam is a hydroelectric dam that spans the Yangtze River near the town of Sandouping in China's Hubei Province. It is the world's largest power station in terms of installed capacity $(22,500 \mathrm{MW})$. The dam is intended to increase the Yangtze River's shipping capacity and reduce the potential for floods downstream by providing flood storage space. The Chinese government regards the project as a historic engineering, social, and economic success. However, the dam flooded archaeological and cultural sites, displaced some 1.3 million people, and is causing significant ecological changes, including an increased risk of landslides. The dam is a controversial topic both domestically and abroad. The National People's Congress approved the dam in 1992. Of 2,633 delegates, 1,767 voted in favour, 177 voted against, 664 abstained, and 25 members did not vote. 
channels to speak in the People's Congresses could express their professional suggestions through Weibo. If there are too many people opposing it [building the Dam], I think that the government will consider [their opinions] instead of making the decision by holding a conference and voting blindly. There must be an effect.

According to the findings, I argue that the internet's capacity for allowing its users to voice and share their opinions may not enhance its users' internal political efficacy, but it increases levels of their collective political efficacy. The majority of participants did not exhibit any belief in their power as individuals to make a difference. However, nine out of 12 participants explicitly articulated their strong belief that online public concern would help to solve the problems and improve the accountability of the government. As Xiaoming put it, the influence of his online viewing and sharing was extremely small, if there was any, but the problem would be more likely to be better solved if it attracted wide attention from the online public. Other participants expressed the same belief in similar words. For example, Yawen said that the government would not risk going against public opinion, if there was consensus among a wide public. Although the participants did not report a belief that they as separate individuals could have a say in the government's decision-making process, they articulated a strong sense that the online public gathered together by the internet could.

Moreover, Xiaoming and Boyu explicitly attributed their increased interest and participation in online political expression, such as concerning themselves with political and social news, sharing information and opinions about social issues, and so on, to their belief in the power of online public opinion. Xiaoming said, 'I don't know how the pressure of public opinion works, but I think that it has an impact when an issue attracts attention from many people. That is why I am concerned about [social and political issues].' Yawen said in the focus group:

However, the government cannot control everything. For example, the case of Li Gang ${ }^{17}$ was exposed [online] and solved. It demonstrated the

Construction started on 14 December 1994. Except for a ship lift, which was completed in December 2015, the dam project was completed and fully functional on 4July 2012.

17 'My Father is Li Gang' is an important online mass incident. On 16 October 2010, 22-yearold Li Qiming, who had been drinking, crashed his car into two students on the Hebei University campus, injuring one and killing the other. After attempting to drive off and being caught by campus security, he reportedly said 'go ahead, sue me if you dare, my dad is [local deputy police chief] Li Gang' (Hassid 2012: 222). The case invoked a massive 
power of media, which have brought about a more just sentence [for the criminal]. Money cannot silence all the problems. If you do so, the public will not accept it. Therefore, [the government] has to explain to the public, it dares not go too far against the public opinion. Sometimes [governmental] coercion does not work.

Boyu expressed how belief in the power of online public opinion induced online political expression. He said, 'if people like us, who are young and active, see such a situation or problem, we like to spread it, from one to ten, and ten to a hundred. I agree with the opinion and my friends agree too. Probably others don't, and then there is a debate.' He also said, 'when some classmates knew something from the internet and continued to spread it through the internet, we discussed it.'

\section{'Public Opinion Online is Powerful'}

Most participants articulated their belief that 'public opinion online is powerful' (Shuhan's words). They reported that the internet provided a channel for internet users to express and spread their opinions and concerns about social issues. They believed that a social problem would attract the attention of the government and receive a better solution when it gained enough public attention online. Yawen said, "[the internet] allows freer speech and allows us to keep a watchful eye on politics, and to discuss politics. It demonstrates how it promotes political transparency and therefore increases justice of some issues.' When explaining where their belief comes from, the participants gave a number of examples of online mass incidents.

Bokai said, 'I think that [public opinion online] has promoting effects.' He supported his belief with the case of the Wenzhou Train Crash. ${ }^{18}$ He said,

outcry both online and offline. Li Qiming was sentenced to six years in jail and ordered to pay the equivalent of $\$ 69,900(£ 44,000)$ in compensation to the family of the dead and $\$ 13,800(£ 8,700)$ to the injured woman (ввС News 2011).

18 The Wenzhou Train Crash was the largest online mass incident in 2011 (Bondes \& Schucher 2014) and attracted wide attention from scholars (e.g. Hassid 2012; Chen 2014; Bondes \& Schucher 2014). On 23 July 2011 two high-speed trains crashed near Wenzhou city, Zhejiang province, killing over 40 people and injuring hundreds. Railway officials tried to cover up the accident and even had the wrecked train cars buried quickly afterwards (Hassid 2012). However, a message about the crash was posted on Sina Weibo just minutes after the crash and 'exploded on Chinese social media almost immediately after the accident' (Bondes \& Schucher 2014: 51). A total of 26 million messages about the tragedy were posted across Chinese microblogging platforms (Hassid 2012; Bondes \& Schucher 2014). The mass online incident resulted in 'a reversed official stance and a more thorough 
'there must be effects $[\ldots]$ because now one measure has been taken. The speed of trains has been reduced.' Shuhan gave two more examples. She explained:

The public opinion online is powerful. Usually those people [with power] might have gotten away [with not following the law] if there had not been public concern online. However, when there is the power of the public, the justice of law is better respected in [the legal process of] similar cases like Yao Jiaxin ${ }^{19}$ and 'My Father is Li Gang' [than when the public opinion is absent]. This is one of the merits of the internet. Usually, such cases go viral online. Everybody knows the cases and shares their concerns. I think that it is good.

Xiaoming, Jinsong, Yuhao, Chenjie, and Yawen listed other examples. Yuhao's example was the case of live extraction of bear bile. He said:

Take Guizhentang live bear bile extracting as an example. The Guizhentang company was supposed to go public on the stock market, but the China Securities Regulatory Commission decided to put the listing plan on hold because too many people opposed it on Weibo.

While scholars are quite sceptical about the positive influence of online mass incidents on the actual solution and addressing the causes of problems (Hassid 2012; Chen 2014), most participants seemed encouraged by those cases to believe in the power of online public opinion. Accordingly, most participants tended to pay attention to social issues, which was evident from the general interest in social and political news among them. All participants reported

investigation' (Hassid 2012). Bondes and Schucher (2014, also cited in Marolt \& Herold 2014) provide two possible explanations for the long and free accumulation of posts on the accident. One is that the online expressions of discontent served as a 'steam valve' for the public. The other is that it resulted from 'the intra-leadership struggles about the reform of the Ministry of Railways.' Analysis of opinions about the Wenzhou train crash expressed by the microbloggers demonstrates the Chinese people's 'growing reluctance to accept the social costs associated with China's growth model, and certain features of the political system such as corruption and a lack of transparency' (Ibid.: 103-104). The pressure of online public opinion is increasingly felt by China's leadership.

19 The case of Yao Jiaxin gained nationwide attention online. On 20 October 2010 in Xi'an city, Shanxi province, Yao Jiaxin, a 2o-year-old third-year university student, knocked down a middle-aged female peasant with his car and stabbed her to death for fear she might remember his number plate. Yao Jiaxin was ultimately sentenced to death and executed. 
that they read social and political news online. They also shared news through various internet applications like instant messaging and social networking websites. All participants reported that they followed, searched for, and shared the big social issues like the Xiaoyueyue Accident and numerous small issues. Sometimes the participants engaged in discussions and posted long comments.

\section{Discussion and Conclusions}

Using six in-depth interviews, a focus group, analysis of web content, and digital auto-ethnography, this study explored how university students use the internet and how they understand the influence of their usage. This article presents findings that help to explain the relationship between internet use, political attitude, and political behaviour, political efficacy, and political expression in particular.

\section{Strangers and Internal Political Efficacy}

The article makes two contributions to better understand the relationship between internet use and internal political efficacy. Previous literature finds the relationship between internet use and political efficacy 'depends on the type of Internet use' (Velasquez \& LaRose 2015: 458). Both online political expression and social media use have been found to be positively associated with internal political efficacy (Kenski \& Stroud 2006; Lee 2006; Velasquez \& LaRose 2015). This article goes one step further. The findings suggest that not all online political expression or social media use contributes to facilitating internal political efficacy in the same way. It can be assumed that, at least in the Chinese context, online political expression on public platforms and with strangers is positively related to internal political efficacy while online political expression with acquaintances is not.

The findings reveal that the anonymity of online political expression and the networking capacity of the internet to allow its users to reach an audience beyond their real life social networks encourage political expression and thus can increase levels of internal political efficacy. Anonymity on a public platform and with strangers is liberating (Wilhelm 1998). It frees internet users from 'the fear of public embarrassment' (Cornfield 2003: 106) and identity boundaries (Papacharissi 2002). Xiaoming's concern about how he was perceived 'on a platform of acquaintances' and how he behaved differently on public platforms with strangers online from how he behaves with acquaintances, provide vivid examples to support the arguments of previous literature. Moreover, Xiaoming's case also supports the argument that the internet does 
encourage some individuals who are politically inactive in real life or in their real-life social network to participate online because it provides a new channel for participation (Stanley \& Weare 2004). The internet expands the scope of some individuals' influence and thus empowers those individuals. It helps to move forward the current debates on whether or not the internet introduces new groups into political participation and whether or not it empowers ordinary individuals (McCormick 2010; Papacharissi 2002; Stanley \& Weare 2004).

However, it is also evident that the participants' online political expression was shaped both by characteristics of the internet and by the government's censorship. Therefore, it is safe to argue that freedom online does not go beyond the line the Chinese government draws. Due to the obscurity and ambiguity of internet censorship in China, two participants articulated different understandings of what is permissible to make public online, and thus exhibited different patterns of online participation.

\section{Online Public, Successful Enactive Experience, and Collective Political Efficacy}

The article extends the concept of political efficacy and enactive experience. According to social cognitive theory, the concept and measurements of political efficacy are not contextless (Bandura 1997; Wollman \& Stouder 1991). Velasquez and LaRose developed the concepts of collective political efficacy (2014) and social media political efficacy (2015), and suggested that the two concepts better predict collective activism and social media activism respectively than political efficacy in general. The findings of this study support their arguments.

Most participants in this study reported a strong belief in their power as the online public. A sense of 'we - the online public' was explicitly articulated among most participants and they tended to believe in their collective power as a group to make a difference and to hold the government accountable through voicing and sharing their opinions on social media. Their reports demonstrate how the internet serves as 'a mechanism' that 'fosters imagined communities' (Quintelier \& Vissers 2008: 414) and how the sense of belonging to an imagined community boosts internet users' collective political efficacy and social media political efficacy. The study provides rich details about how the participants articulated their efficacy beliefs, providing a backdrop for further research to develop measurements of collective political efficacy and social media political efficacy in the context of China.

The study also casts light on the relationship between enactive experiences and efficacy beliefs. Existing literature supports reciprocal effects between participation and political efficacy (Finkel 1985; Velasquez \& LaRose 2015). There 
is empirical evidence that successful enactive experiences lead to increased levels of internal political efficacy. When explaining where their belief in the power of the online public comes from, the participants gave a number of examples of online mass incidents. They perceived that the online public have successfully influenced the outcomes of the incidents in a good way. According to the findings, it is plausible that perceived successful enactive experiences of a group or an imagined community enhance individuals' collective political efficacy if they have a sense of belonging to that group. Moreover, the enactive experiences do not need to actually be successful, but must be perceived to be successful.

To interpret the results in a positive light, it is safe to assume that the internet can serve to enhance internet users' collective political efficacy and participation, and that the effect is mediated by the perceived successful enactive experience of the online public. In such a sense, the internet in China promotes political participation in China. However, the participants' perception of the success of the online public can be an illusion, due to their ignorance or as a result of the intentional spin of the government (McCormick 2010). If that is the case, the mechanism favours the government more than the Chinese people.

\section{Limitations and Further Research}

There are two limitations of the study: firstly, it takes a social constructive approach, in which most of the arguments are based on the participants' selfreports, and secondly, the small sample size does not allow generalization. The findings provide nuanced details for further research to develop contextual measurements of concepts of political efficacy beliefs in China. Survey and online data mining can be employed to test the assumptions that emerge from the study among larger populations or other groups of internet users.

In addition to what is presented in this article, the study also finds that university students disengage from political activities for both practical reasons, such as a lack of opportunity or a lack of interest, and ideological concerns, such as their view that democratization has to necessarily be a radical, revolutionary process and that individuals are powerless to bring about such a revolution (what we might call a 'revolutionary view' of democracy). Our study reveals patterns in the way various internet applications are employed by an individual to achieve one goal, and how a politically sensitive message travels through various platforms online. More importantly, it shows that seemingly trivial online exchanges may contribute to a changing social and political environment, albeit in ways that the interviewees themselves may not describe as 'democratizing'. Provided with certain conditions, online entertainment and 
political disengagement can be a way to promote democratization, given its potential to create a plural ideational climate, and to increase discontent with the current situation by facilitating social comparison.

\section{References}

Abramson, Paul R. \& John H. Aldrich (1982), 'The Decline of Electoral Participation in America'. American Political Science Review, 76, 502-521.

Almond, Gabriel A. \& Sidney Verba Sidney (1963), The Civic Culture: Political Attitudes and Democracy in Five Nations, An Analytic Study. Princeton: Princeton University Press.

Bandura, Albert (1997), Self-efficacy: The Exercise of Control. New York: NY, W. H. Freeman.

Bandura, Albert (2001), 'Social Cognitive Theory of Mass Communication'. Mediapsychology, 3, 265-299.

ввС News (2011, January 30), 'China Hit-and-Run Driver Sentenced to Six Years in Jail'. BBC News, retrieved 16 March 2012 from http://www.bbc.com/news/ world-asia-pacific-12317756.

Bennett, Lance W. (1975), The Political Mind and the Political Environment. Lexington, MA.: Lexington Books.

Bennett, Linda L. M. \& Stephen E. Bennett (1989), 'Enduring Gender Differences in Political Interest: The Impact of Socialization and Political Dispositions'. American Politics Research, 17, 105-122.

Bodeen, Christopher (2012, March 15), 'Flashy Style Seen Behind Downfall of China's Bo'. Associated Press, retrieved 16 March 2012 from http://finance.yahoo.com/news/ flashy-style-seen-behind-downfall-163208672.html.

Bondes, Maria \& Günter Schucher (2014), 'Derailed Emotions: The Transformation of Claims and Targets during the Wenzhou Online Incident'. Information, Communication \& Society, 17(1), 45-65.

Brunsting, Suzanne \& Tom Postmes (2002), 'Social Movement Participation in the Digital Age'. Small Group Research, 33(5), 525-554.

Campbell, Angus; Gurin, Gerald, \& Warren E. Miller (1954), The Voter Decides. Evanston, Ill.: Row, Peterson.

Caprara, Gian Vittorio, Vecchione, Michele, Capanna, Cristina, \& Minou Mebane, (2009), 'Perceived Political Self-Efficacy: Theory, Assessment, and Applications'. European Journal of Social Psychology, 39(6), 1002-1020.

Chen, Wenhong (2014), 'Taking Stock, Moving Forward: The Internet, Social Networks and Civic Engagement in Chinese Societies'. Information, Communication \& Society, $17(1), 1-6$. 
Cockain, Alex (2014), 'Regarding Subjectivities and Social Life on the Screen: The Ambivalences of Spectatorship in the People's Republic of China'. In: Peter Marolt \& David K. Herold (ed.), China Online: Locating Society in Online Spaces. London and New York: Routledge (pp. 49-66).

Cohen, Aaron, Vigoda, Eran, \& Aliza Samorly (2001), 'Analysis of the Mediating Effect of Personal-Psychological Variables on the Relationship between Socioeconomic Status and Political Participation: A Structural Equations Framework'. Political Psychology, 22(4), 727-757.

Cornfield, Michael (2003), 'Adding in the Net: Making Citizenship Count in the Digital Age'. In: David M. Anderson \& Michael Cornfield (ed.), The Civic Web: Online Politics and Democratic Values. Lanham, MD: Rowman \& Littlefield (pp. 97-112).

Coyne, Imelda T. (1997), 'Sampling in Qualitative Research. Purposeful and Theoretical Sampling; Merging or Clear Boundaries?' Journal of Advanced Nursing, 26, 623-630.

Dahlgren, Peter (2005), 'The Internet, Public Spheres, and Political Communication: Dispersion and Deliberation'. Political Communication, 22(2), 147-162.

Donald, Stephanie, Keane, Michael, \& Yin Hong (2002), Media in China: Consumption, Content and Crisis. London: Routledge Curzon.

Dutta-Bergman, Mohan J. (2005), 'Access to the Internet in the Context of Community Participation and Community Satisfaction'. New Media \& Society, 7(1), 89-109.

Finkel, Steven E. (1985), 'Reciprocal Effects of Participation and Political Efficacy - A Panel Analysis'. American Journal of Political Science, 29(4), 891-913.

Glaser, Barney G. (1978), Theoretical Sensitivity: Advances in the Methodology of Grounded Theory. Mill Valley, Calif.: The Sociology Press.

Guo, Liang, Stefaan, Verhulst, Chang, Huili, \& Bo Gai (2007), Surveying Internet Usage and its Impact in Seven Chinese Cities. Beijing: Chinese Academy of Social Sciences.

Hassid, Jonathan (2012), 'Safety Valve or Pressure Cooker? Blogs in Chinese Political Life'. Journal of Communication, 62(2), 212-230.

Hong, Yan, Li, Xiaoming, Mao, Rong, \& Bonita Stanton (2007), 'Internet Use Among Chinese College Students: Implications for Sex Education and HIV Prevention'. CyberPsychology \& Behavior, 10(2), 161-169.

Iyengar, Shanto (1980), 'Subjective Political Efficacy as a Measure of Diffuse Support'. Public Opinion Quarterly, 44(2), 249-256.

Kenski, Kate \& NatalieJ. Stroud (2006), 'Connections between Internet Use and Political Efficacy, Knowledge, and Participation'. Journal of Broadcasting \& Electronic Media, $50(2), 173-192$.

King, Nigel \& Horrocks, Christine (2010), Interviews in Qualitative Research. London: SAGE.

Lee, Kwan M. (2006), 'Effects of Internet Use on College Students' Political Efficacy'. CyberPsychology and Behavior, 9(2), 415-422. 
Leighley, Jan E. (1995), 'Attitudes, Opportunities and Incentives: A Field Essay on Political Participation'. Political Research Quarterly, 48(1), 181-209.

Lippa, Barbara (Ed.) (2008), eParticipation Evaluation and Impact. The DEMO-net Consortium.

Xinhua News (2012, September 24), 'Wang Lijun Sentenced to 15 Years in Prison'. Xinhua News, retrieved 16 March 2012 from http://news.xinhuanet.com/english/ china/2012-09/24/c_131868689.htm.

McCormick, Barrett L. (2010), 'Technological Empowerment: The Internet, State, and Society in China'. Review of Policy Research, 27(1), 89-91.

Morgan, David L. (1988), Focus Groups as Qualitative Research. Newbury Park, CA \& London: Sage.

Morse, Janice M. (1991), Qualitative Nursing Research: A Contemporary Dialogue. Newbury Park, CA. \& London: Sage Publications.

Ng, Jason Q. (2013), Blocked on Weibo: What Gets Suppressed on China's Version of Twitter (And Why). New York, London: The New Press.

Norris, Pippa \& David Jones (1998), 'Virtual Democracy'. Harvard International Journal of Press-Politics, 3(2), 1-4.

Papacharissi, Zizi (2002), 'The Virtual Sphere: The Internet as a Public Sphere'. New Media \& Society, 4(1), 9-27.

Quintelier, Ellen \& Vissers, Sara (2008), 'The Effect of Internet Use on Political Participation: An Analysis of Survey Results for 16-Year-Olds in Belgium'. Social Science Computer Review, 26(4), 411-427.

Richey, Sean \& Zhu, Junyan (2015), 'Internet Access Does Not Improve Political Interest, Efficacy, and Knowledge for Late Adopters'. Political Communication, 32(3), 396-413. Rosenthal, Elisabeth (2002, March 24), 'Under Pressure, Chinese Newspaper Pulls Exposé on a Charity'. The New York Times, retrieved 8 June 2013 from: http://www .nytimes.com/2002/03/24/world/under-pressure-chinese-newspaper-pulls-exposeon-a-charity.html.

Shah, Dhavan V., Kwak, Nojin, \& Lance R. Holbert (2001), “'Connecting” and "Disconnecting" with Civic Life: Patterns of Internet Use and the Production of Social Capital'. Political Communication, 18(2), 141-162.

Stanley, Woody J. \& Christopher Weare (2004), 'The Effects of Internet Use on Political Participation - Evidence from an Agency Online Discussion Forum'. Administration \& Society, 36(5), 503-527.

Stewart, David W. \& Prem N. Shamdasani (1990), Focus Groups: Theory and Practice. Newbury Park; London: Sage.

Strauss, Anselm L. \& Juliet M. Corbin (1990), Basics of Qualitative Research: Grounded Theory Procedures and Techniques. Newbury Park, CA. \& London: Sage.

Tong, James (2003), 'The Gender Gap in Political Culture and Participation in China'. Communist and Post-Communist Studies, 36(2), 131-150. 
Velasquez, Alcides \& Robert LaRose (2014), 'Youth Collective Activism through Social Media: The Role of Collective Efficacy'. New Media \& Society, 17(6), 899-918.

Velasquez, Alcides \& Robert LaRose (2015), 'Social Media for Social Change: Social Media Political Efficacy and Activism in Student Activist Groups'. Journal of Broadcasting \& Electronic Media, 59(3), 456-474.

Verba, Sidney \& Norman Nie (1972), Participation in America. New York: Harper \& Row. Verba, Sidney, Schlozman, Kay L., \& Henry E. Brady (1995), Voice and Equality: Civic Voluntarism in American Politics. Cambridge, MA: Harvard University Press.

Wilhelm, Anthony G. (1998), 'Virtual Sounding Boards: How Deliberative is Online Political Discussion?' Information, Communication, and Society, 1(3), 313-338.

Wollman, Neil \& Robin Stouder (1991), 'Believed Efficacy and Political Activity: A Test of the Specificity Hypothesis'. Journal of Social Psychology, 131(4), 557-566.

Wu, Chung-Li (2003), 'Psycho-Political Correlates of Political Efficacy: The Case of the 1994 New Orleans Mayoral Election'. Journal of Black Studies, 33(6), 729-760.

Yang, Guobin (2003), 'The Co-evolution of the Internet and Civil Society in China'. Asian Survey, 43(3), 405-422.

Yee, Herbert S. (1999), The Political Culture of China's University Students: A Comparative Study of University Students in Mainland China, Hong Kong, Macau, and Taiwan. Commack, NY: Nova Science.

Yip, Martin (2011, October 21), 'Anger and Debate over Hit-and-Run Toddler Wang Yue'. $B в C$, retrieved 16 March 2012 from http://www.bbc.co.uk/news/ world-asia-pacific-15401055. 